www.ufaw.org.uk

\title{
Awareness concerning optimal pig production management and animal welfare among smallholder farmers in Tanzania
}

\author{
UC Braae* ${ }^{* \dagger}$, M-L Penrith ${ }^{\ddagger}$, HA Ngowi ${ }^{\S}$, F Lekule" and MV Johansen ${ }^{\dagger}$
}

\author{
† Section for Parasitology and Aquatic Diseases, Department of Veterinary Disease Biology, Faculty of Health and Medical Sciences, \\ University of Copenhagen, DK-1870 Frederiksberg, Denmark \\ ₹ Department of Veterinary Tropical Diseases, University of Pretoria, South Africa \\ $\S$ Department of Veterinary Medicine and Public Health, Faculty of Veterinary Medicine, Sokoine University of Agriculture, Morogoro, Tanzania \\ \# Department of Animal Science and Production, Faculty of Agriculture, Sokoine University of Agriculture, Morogoro, Tanzania \\ * Contact for correspondence and requests for reprints: braae@sund.ku.dk
}

\begin{abstract}
The aim of this study was to assess smallholder farmer awareness in terms of good pig management and to identify serious management issues that should be readily changeable despite resources being limited in a rural setting. Methodology was a combination of questionnaire and observational surveys performed at pig-keeping households practising either confinement or a free-range system. Households were identified using the snowball method. A total of 120 pig-keeping households were included, of which 32 practised free-range systems and 88 confined their pigs. The observational survey included management practices and welfare assessment based on one pig from each of the 120 households. The results indicated that farmers were not aware of the basic requirements of pigs regardless of the production system practised. Water was often neglected and provided less frequently among those practising free-range. Pigs kept free-range also received treatment less frequently compared to those kept confined. Pigs were generally kept in poor conditions with risk of injury and without shelter from wind, rain, cold, heat, and sun. Welfare issues exist within both production systems, but issues within the confinement system could be easily eliminated with proper management. More knowledge on basic pig husbandry is required in the region and is essential for improving production. Educating farmers on the basic requirements for water and feed, alone, could vastly improve smallholder pig production. Education on pig management should therefore be a cornerstone in any research activity involving smallholder farmers in rural areas.
\end{abstract}

Keywords: Africa, animal welfare, feed, production systems, stocking density, water

\section{Introduction}

Over the last few decades, sub-Saharan livestock production has shifted away from ruminants, with monogastric livestock species becoming more prevalent. The estimated number of cattle has climbed, in the past four decades, from 153 to 301 million, whereas the number of pigs increased from 7.8 to 35 million, a per capita decrease in the number of cattle, but an increase in the per capita number of pigs (FAOSTAT 2014). This trend is a direct result of increased pressure on land suitable for grazing animals, due to urban development, competition, and lack of water resources. Compared to cattle, pigs are more suitable for keeping in urban areas, and growth and feed conversion rates are higher. This has resulted in increased investments in pig production stimulated by increasing demands for pork and live pigs. Unfortunately, smallholder pig production has been synonymous with poor growth and low slaughter weights. Pig production in most low-income countries is constrained by inaccessibility to advice and guidance from livestock advisors (Kagira et al 2010; Karimuribo et al 2011; Muhanguzi et al 2012).
In Tanzania, pig production is primarily on a smallholder scale. The estimated national pig population is 2 million (2014), of which Mbeya Region holds over 20\% and is, therefore, the most important pig-producing region in Tanzania (URT 2014). Mbeya Region has seen a large increase in the number of smallholder farmers since the introduction of Danish Landrace pigs in the 1970s. Pigs are kept almost exclusively by smallholder subsistence crop farmers as a secondary enterprise. There are two types of smallholder pig production systems: a confinement production system where pigs are confined all year in pens, and a free-range production system where pigs roam depending on season. When not left to roam, pigs are kept either in pens or tethered. Studies relating to disease prevalence within these two systems have been performed (Ngowi et al 2004; Braae et al 2013; Komba et al 2013; Kabululu et al 2015), but no studies have assessed farmer awareness of proper pig management in a rural smallholder setting of Tanzania, although welfare issues among farm animals in Tanzania have been described in general (Wilson 2013). An animal's welfare can be evaluated using the Five Freedoms: (1) 
Table I Farmer responses to questions related to pig management issues within two types of production systems.

\begin{tabular}{|c|c|c|c|c|}
\hline \multicolumn{2}{|c|}{ Management issues } & \multirow{2}{*}{$\begin{array}{l}\text { Confinement system } \\
\text { Frequency (\%) } \\
2(2)\end{array}$} & \multirow{2}{*}{$\begin{array}{l}\text { Free-range system } \\
\text { Frequency (\%) } \\
0(0)\end{array}$} & \multirow{2}{*}{$\begin{array}{l}\text { Both systems } \\
\text { Frequency (\%) } \\
2(2)\end{array}$} \\
\hline Water provisions & Continuously & & & \\
\hline & Thrice daily & $0(0)$ & $2(6)$ & $2(2)$ \\
\hline & Twice daily & $19(22)$ & $4(12)$ & $23(19)$ \\
\hline & Once daily & $56(64)$ & $8(25)$ & $64(53)$ \\
\hline & Less than daily & $9(10)$ & $5(16)$ & $14(12)$ \\
\hline & Never & $2(2)$ & $13(4 \mid)$ & $15(12)$ \\
\hline & Total & $88(100)$ & $32(100)$ & $120(100)$ \\
\hline \multirow[t]{4}{*}{ Feed provisions } & Twice daily & $23(26)$ & $16(52)$ & $39(33)$ \\
\hline & Once daily & $64(74)$ & $14(45)$ & $78(66)$ \\
\hline & Never & $0(0)$ & I (3) & $\mathrm{I}(\mathrm{I})$ \\
\hline & Total & $88(100)$ & $32(100)$ & $120(100)$ \\
\hline \multirow[t]{4}{*}{ Treatment last 12 months } & Preventative & $58(66)$ & $6(19)$ & $64(53)$ \\
\hline & Curative & $13(15)$ & $4(12)$ & $17(14)$ \\
\hline & Never & $17(19)$ & $22(69)$ & $39(32)$ \\
\hline & Total & $88(100)$ & $32(100)$ & $120(99)$ \\
\hline \multirow[t]{3}{*}{ Veterinary visitation last 12 months } & Yes & $36(4 I)$ & $7(22)$ & $43(36)$ \\
\hline & No & $52(59)$ & $25(78)$ & $77(64)$ \\
\hline & Total & $88(100)$ & $32(100)$ & $120(100)$ \\
\hline
\end{tabular}

Freedom from hunger and thirst; (2) Freedom from discomfort; (3) Freedom from pain, injury, or disease; (4) Freedom from fear and distress; and (5) Freedom to express normal behaviour (FAWC 2009). Four principles have also been identified for use in animal welfare assessment and they are: Good feeding, Good housing, Appropriate behaviour, and Good health (Welfare Quality® 2009). Poor animal welfare can have serious consequences for production output, but often can be simply solved through improved management. However, the problems that exist under smallholder management and the farmers' awareness of such problems are unknown. The aim of this study was, therefore, to assess farmer awareness of good pig management and identify management problems that could lead to poor animal welfare under the different production systems used among smallholder pig producers in Mbeya Region, Tanzania.

\section{Materials and methods}

\section{Study area}

This study was carried out in Mbeya Region, Tanzania, in Mbeya and Mbozi districts located between latitudes $8^{\circ} 14^{\prime}$ and $9^{\circ} 24^{\prime} \mathrm{S}$ and longitudes $32^{\circ} 04^{\prime}$ and $33^{\circ} 49^{\prime} \mathrm{E}$. Mbeya Region has a sub-tropical climate with the wet season stretching from November to May. Both districts are rural areas where pig production is almost exclusively on a smallholder level.

\section{Study design and sample size}

This work was performed as a cross-sectional study during the dry season from May to August 2011, consisting of a questionnaire survey combined with an observational study carried out at the same households. Smallholder households keeping pigs were chosen as the unit of interest, with those selected practising confinement production systems in Mbeya district and free-range production systems in Mbozi district. Households confining pigs were chosen from 22 villages in Mbeya district known to keep pigs, using the 'snowball' method as described by Sikasunge et al (2007), where the first farmer in each village was asked to locate other farmers among acquaintances until four households had been identified. Seven villages from Mbozi district were included in the study and all farmers practising freerange within the villages were included in the study.

\section{Questionnaire survey}

A structured questionnaire survey was carried out among pig-keepers to obtain information on knowledge, percep- 
tions, and attitudes on feed and different types of feed used, water provision and the frequency thereof, by asking how often they provided water and feed to their pigs and what type of feed they provided. General needs of pigs were explored, such as confinement under proper sanitary conditions and requirements for protection against the environment, contact to local veterinarians, record-keeping on, eg dates of service and treatment, treatment types and history thereof and which drugs were used, and farmers' perception on current disease status of the pig. Farmers were asked in an open-ended question to name the four most important requirements they provided for their pigs, in order of importance. The answers reflected perceptions about basic pig husbandry requirements. Interviews were conducted by the same interviewer in Swahili or translated into the local tribal language when necessary. For the questionnaire, see supplementary material to papers published in Animal Welfare on the UFAW website: http://www.ufaw.org.uk/theufaw-journal/supplementary-material.

\section{Observational study}

An observational study was performed to explore farmer practices regarding management, such as number of pigs, availability of water, and quality of pens in terms of size, flooring, shelter, roof and shade. One pig, at least three months of age, was randomly chosen using a lottery system from each household to assess the general health status of the herd. General health according to a body condition score of the pigs was recorded on a scale of $1-5$, which was an adaptation from BPEX (2009), based on the appearance and palpation of ribs, hips, and backbone in the following order: 1) (emaciated) hips, ribs and backbone visible; 2 ) (thin) hips and backbone noticeable and easily felt; 3 ) (somewhat thin) hips and backbone felt without palm pressure; 4) (normal) hips and backbone only felt with firm palm pressure; and 5) (good condition) hips and backbone only felt with difficulty. Pigs were registered, photographed and examined for lesions. Sows that were pregnant or had just farrowed were excluded from the study in order to avoid causing distress to the sow or piglets, or interfere with the palpation score.

\section{Data analysis}

Differences in water provision frequencies between production systems, ie confinement and free-range were analysed using the Mann-Whitney $U$-test. Feeding was categorised as provided/not provided and compared between production systems using Fisher's exact test. Differences in the use of treatment and current disease status between production systems were analysed using Fisher's exact tests. Contact with a veterinarian was compared between confinement and freerange production systems using the Chi-squared test. Obtained weight and lesion scores of pigs were each compared between production systems using the Mann-Whitney $U$-test.

\section{Results}

In total, 120 smallholder households and pigs were surveyed, 88 households practising confinement located in 22 villages in Mbeya district and 32 households practising free-range located in seven villages in Mbozi district.

\section{Questionnaire survey}

There was a significant difference in the frequencies of water distribution between the two production systems $(P<0.001)$. Among farmers practising a free-range system, $41 \%$ of the pigs were left to find water for themselves. The farmers who did provide water for the pigs most often did so once a day. Within the confinement system, $64 \%$ of farmers gave water to the pigs once a day, $24 \%$ gave water more frequently than that, but $10 \%$ provided water less than once a day, and $2 \%$ stated that they never provided the pigs with water (Table 1).

Feed was provided to the pigs 1-2 times daily in the majority $(99 \%)$ of the households, but among the farmers practising free-range, one stated that he never provided the pigs with feed (Table 1). Within the confinement system, $74 \%$ fed their pigs once a day and the rest of the farmers (26\%) fed the pigs 2-3 times a day. None of the households used any commercially produced feedstuff. Maize bran was stated to be the most important feed type available regardless of season among $95 \%$ of the households.

Treatment for intestinal helminths and ectoparasites, either curative or preventive, had been performed by $67 \%$ of the farmers within the last year. Significantly more farmers practising confinement $(81 \%)$ used treatment compared to those practising free-range $(31 \%)(P<0.001)$. Of the farmers using treatment, more than $80 \%$ had used injectable ivermectin. Acaricidal spray (amitraz) was also used. Parasite treatment was mainly carried out by government extension officers - primarily trained as agronomists $(44 \%)$ or private veterinary workers $(42 \%)$, both operating on a cost recovery system. Of the 120 households, $84 \%$ stated that they had no current disease problem within the herds, with no difference between production systems $(P=0.396)$. Contact with a local veterinarian was sought by $36(41 \%)$ of those practising confinement and 7 (22\%) of those practising free-range, but the difference was not significant $(P=0.088)$. Few farmers kept records in relation to their pigs (7\%). Records that were kept were in relation to breeding, such as service and farrowing dates. One farmer stated that he kept a record of profit and loss and dates of treatment, but could not produce the record at time of visit.

When farmers were asked what they provided for their pigs in order of importance (1-4), feed was mentioned by the majority (97\%) as the most important item regardless of production system. Among the farmers practising confinement, $12 \%$ were able to mention four items compared with farmers who practised free-range, who were unable to mention more than two items. Overall, treatment of pigs was mentioned as important by $42 \%$ of the farmers. Water was stated to be important by 23 and $13 \%$ of the farmers practising confinement and free-range, respectively (Table 2). Other items mentioned by the farmers were providing good sanitary conditions for the pigs by cleaning the pen, providing the sow with a boar for service, and providing adequate shade for the pigs during the day. 
Table 2 Answers given by 120 farmers when asked what they provide for their pigs in order of importance I-4. Farmers constituted 88 practising a confinement production system and 32 practising a free-range production system, at the time of visit.

\begin{tabular}{|c|c|c|c|c|c|c|c|c|}
\hline & \multicolumn{8}{|c|}{ Percentages for farmers practising a confinement production system } \\
\hline & Feeds & Treatment & Water & Minerals & Confinement & Other & No answer & Total \\
\hline $\mathrm{T}$ & 95 & 5 & 0 & 0 & 0 & 0 & 0 & 100 \\
\hline 2 & 0 & 39 & 23 & 8 & 5 & 0 & 26 & $101 *$ \\
\hline 3 & 0 & 13 & 0 & 5 & 16 & 6 & 61 & $101 *$ \\
\hline \multirow[t]{3}{*}{4} & 0 & 0 & 0 & 3 & 3 & 6 & 88 & 100 \\
\hline & \multicolumn{8}{|c|}{ Percentages for farmers practising a free-range production system } \\
\hline & Feeds & Treatment & Water & Minerals & Confinement & Other & No answer & Total \\
\hline T & 100 & 0 & 0 & 0 & 0 & 0 & 0 & 100 \\
\hline 2 & 0 & 3 & 13 & 16 & 0 & 0 & 69 & $101 *$ \\
\hline 3 & 0 & 0 & 0 & 0 & 0 & 0 & 100 & 100 \\
\hline 4 & 0 & 0 & 0 & 0 & 0 & 0 & 100 & 100 \\
\hline
\end{tabular}

* Differs from $100 \%$ due to rounding.

\section{Observational study}

Farmers kept, on average, 2.6 pigs under both the confinement and free-range production systems. However, approximately $38 \%$ kept only one pig and $53 \%$ of the pigs did not have contact with other pigs. Most pigs (93\%) were phenotypically European Large White or Landrace (exotic crossbreeds). Of the 120 households visited, only one pig had access to water at the time of the visit.

Within the confinement production system, the majority of pens were poorly constructed and lacked shelter, $22 \%$ were without roofs, and therefore offered limited access to shade during the warmest part of the day (Figure 1). Floors within the pens were often uneven with large gaps and nails protruding from the floorboards (Figure 2). The stocking density, defined as square meters $\left(\mathrm{m}^{2}\right)$ of floor space available per pig within the pen, was calculated for all pens. The overall median stocking density was $1.89 \mathrm{~m}^{2}$ (mean $3 \mathrm{~m}^{2}$ ) and ranged from $0.34-9.60 \mathrm{~m}^{2}$. Pigs kept in the pens were mostly growing pigs, with a few farmers keeping a sow for breeding. Among the farmers practising free-range systems, pigs were often improperly tethered with skin lesions from chafing ropes (Figure 3).

Approximately $48 \%$ of the pigs within both production systems were classified as being below the normal body condition, with $23 \%$ somewhat thin, $21 \%$ thin, and $4 \%$ emaciated. Within the confinement production system, $52 \%$ of the pigs were considered to have a body condition below normal and $5 \%$ of those were classified as emaciated. Among the free-range pigs, $38 \%$ were classified as having a body condition below normal, but none were found to be emaciated.

\section{Discussion}

The study showed that smallholder farmers in Mbeya Region lacked awareness of proper pig management and the basic requirements necessary to safeguard the welfare of an animal, as outlined by the Five Freedoms, were not met. The communities would benefit from education on the basic needs of pigs in terms of adequate supply of food and water, as well as on proper pen construction to provide pigs with shelter from cold, heat, sun, wind, and rain. Most of these issues could be ameliorated despite resources being limited in the smallholder setting, and the benefits likely to be great.

Whereas many scientific publications on feed optimisation are available, water requirements and management are hardly ever addressed. Resources are needed to disseminate research findings to the local communities in an accessible way. Education of extension officers working in the rural communities could be of great benefit in this matter.

From our results, pig management is sub-optimal within both production systems. Pigs are prevented from expressing natural behaviour if they are confined in small pens. More than half of the pigs were kept without access to social contact with other pigs, which constitutes a welfare problem and might result in performance problems (Hemsworth et al 1978). Limited resources prevent some farmers from keeping more than one pig, but this problem might be solved by instigating part-ownership farms. Although smallholder pigs in this study had, on average, more space compared with pigs from high intensity farms (1.0-1.3 $\mathrm{m}^{2}$ for grower/finisher pigs) (Knoesen et al 1993), stocking density obtained in this study might have been biased by the large reduction of the pig population caused by an outbreak of African swine fever just prior to the study. 
Figure I

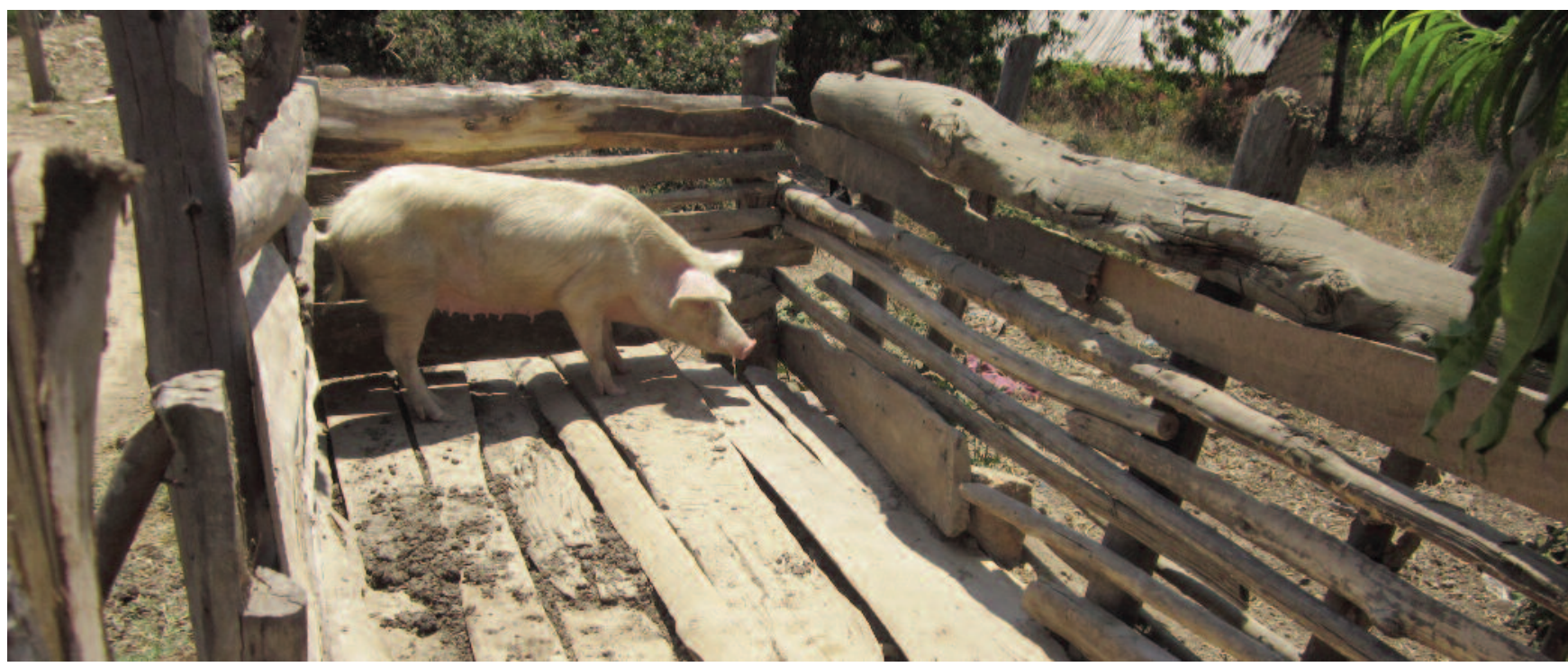

Pigs confined in a poorly constructed shelter without roof and with limited access to shade during the warmest part of the day.

Figure 2

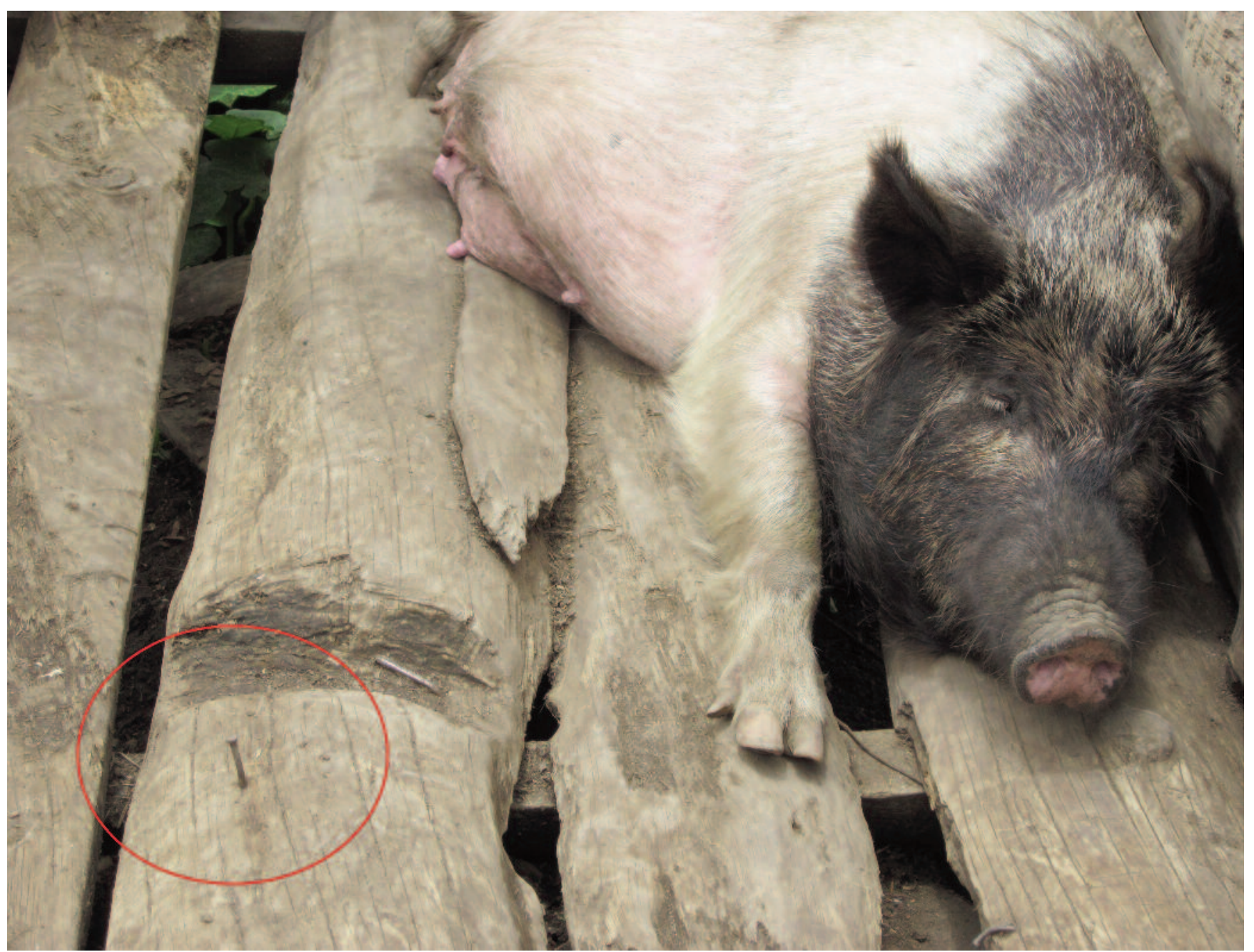

Floors of pen with a protruding nail and large gaps between the floorboards. 
Figure 3

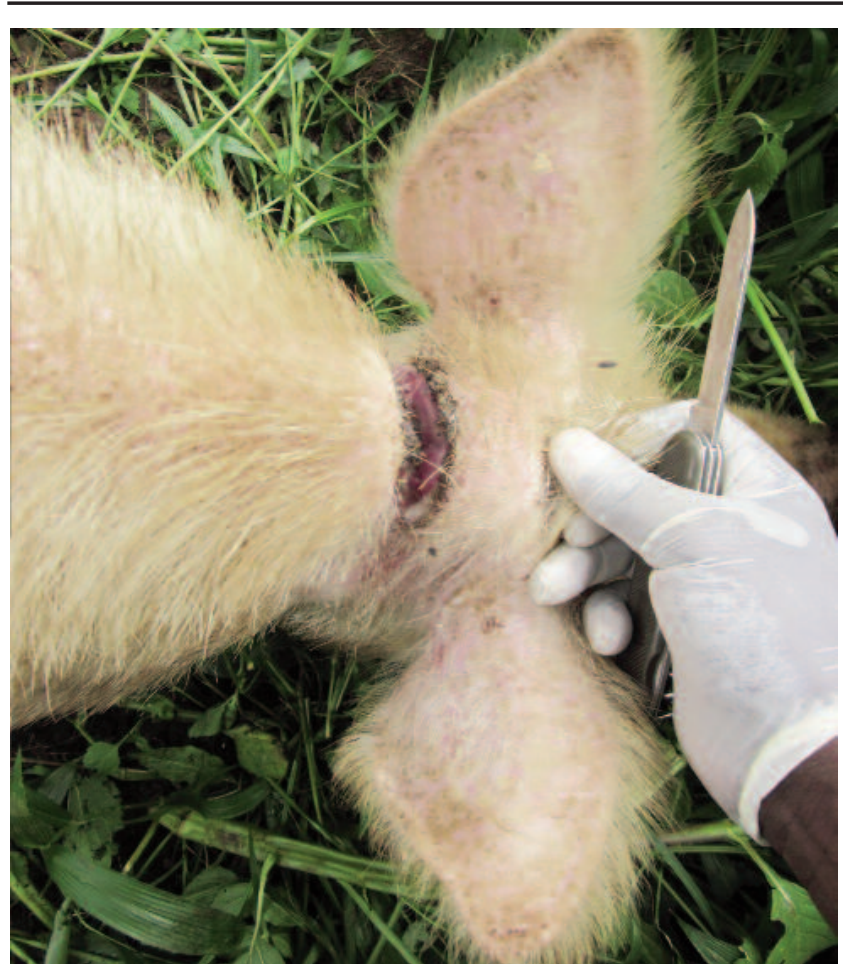

Skin lesion from a chafing rope after improper tethering.

Confined pigs are protected from people and animals that might harm them, but pigs can suffer injuries within the pens because of poorly constructed or maintained flooring, which was observed during this study. Confined pigs often had little or no access to shade and pens lacked shelter from weather extremes. Lack of shade is a particular welfare problem because the majority of the pigs were exotic, white-skinned crossbreeds that have limited tolerance to sun exposure and can suffer severe sunburn. Easily accessible construction guidelines informing farmers how to construct proper enclosures could relieve these problems.

Free-ranging pigs were often inappropriately tethered for part of the year because of the cropping season, leaving them with deep wounds and risk of secondary infection. Arguably, this could be solved by fitting pigs with proper harnesses that would minimise the risk of wounds occurring from tethering. The free-range production system gives pigs an opportunity to scavenge for food and seek out water, but also puts them at risk of serious diseases, such as porcine cysticercosis, which is highly prevalent within the area (Braae et al 2013, 2014; Kabululu et al 2015). In our opinion, free-ranging pigs kept in the manner observed in this study, should be discouraged, both from the point of view of animal welfare as well helping to ensure food safety. Farmer education is required to inform about the potential risks of such a practice (Figure 3).

Confined pigs rely completely on the owners' care for water and feed. However, farmers perceived feed and treatment to be more essential than satisfying the basic need for water. Pigs in both types of production systems were fed inadequately and water provision was insufficient in terms of quantity and frequency based on both observations and farmers' own statements. Water was rarely mentioned as something the farmers perceived to be important to provide to the pigs. A few even stated that pigs do not require water. Appropriate water provision for pigs is important for welfare considerations and to achieve optimal production, and varies according to breed, stage of production, feed and climate (Patience 2012; Nannoni et al 2013). Recommendations based on the ratio of water to feed (eg $2.56 \mathrm{~L} \mathrm{~kg}^{-1}$ of feed for pigs 10-22 weeks old) (Schlink et al 2010) are only applicable to pigs fed weighed portions of a commercial ration. Published guidelines for daily water supply vary from 0.5-2 L in piglets, 5-9 L per day in growing and finishing pigs, $5-11 \mathrm{~L}$ in boars and non-pregnant or pregnant sows, and $15-20 \mathrm{~L}$ or more in lactating sows (Vosloo \& Casey 1993; Schlink et al 2010), as the intake of lactating sows has been shown to vary between 12 and $40 \mathrm{~L}$ (Schlink et al 2010). However, these requirements increase with temperature, and under tropical conditions, an increase of two to four times the temperate climate averages may be expected depending on age and stage of production. According to statements made by farmers and based on observations, the water volumes provided for the pigs of Mbeya and Mbozi districts were nowhere near these guidelines. This is likely to be a serious welfare problem and an important constraint, especially with regard to piglet mortality as sows provided with insufficient quantities of water will not produce enough milk for lactation, leading to piglet death (Fraser et al 1990). For growing pigs, insufficient water provision can lead to reduced feed intake, which will slow the growth rate (Lynch et al 2006). Similar conditions have been reported from Lao PDR, where insufficient provision of water was also considered a constraint in smallholder pig production (Phengsavanh et al 2010). Other studies investigating smallholder production in Kenya and in Tanzania failed to mention quantity or frequency of water provision (Kagira et al 2010; Wabacha et al 2004a,b). A study in Uganda indicated that the majority of farmers interviewed (> 85\%) did provide water for their pigs at least once a day, but amounts were not reported (Muhanguzi et al 2012). Simple education on the water requirements of pigs would conjecturally increase both the welfare of the pigs and production yield. This could be facilitated through existing government livestock extension workers in place in Tanzanian districts.

Among the farmers practising confinement, pigs were generally fed once a day. Within both production systems farmers were in agreement about feed being the most important requirement they provided to the pigs. Both feeding frequencies and quantities of feed given might increase at other times of year. The study was performed just before harvest, a time when stocks of feed are low, which could result in periodical underfeeding. No information was obtained on the amount of feed given to the pigs. However, based on the pigs' body condition, they were generally inadequately fed. This was is in accordance with the trend that the body condition of free-range pigs, which had the opportunity to forage, was better than that of confined pigs. Based on farmers' statements, the most 
important feed type available was maize bran, which constituted a large part of the diet. In Mbozi district where pigs were kept under free-range systems, some farmers would leave the pigs to fend entirely for themselves in terms of water and, in the case of one farmer, feed, although $99 \%$ of farmers did provide feed 1-2 times a day. Similarly, smallholder farmers in Lao PDR commonly provided their pigs with feed twice a day, but underfeeding was often observed (Phengsavanh et al 2010). In a recent description of local feeding systems on smallholder farms in Kenya, pigs were fed once or twice a day, and water was provided separately with the food (Mutua et al 2012), which is comparable to Mbeya Region. Improved local feeds have been suggested to increase production output at the smallholder level (Lekule \& Kyvsgaard 2003). However, on the basis of the present study, we believe that education of farmers on the basic requirements of water and feed quantity alone could hugely improve smallholder pig production. The study was limited by the outbreak of African swine fever, making it difficult to increase the number of pig-keeping households. Endoparasitic status was not investigated and could be a confounder in assessing under-feeding.

Injectable ivermectin was commonly used as treatment for ectoparasites and helminths and few farmers stated that they had existing disease problems at the time of the visit, but ectoparasites were often seen. In a recent study in the same area, Kabululu et al (2015) found that parasitoses constituted a major burden for smallholder pigs in Mbeya Region and major risk factors included infrequent antiparasitic treatment, poor pen hygiene, and poor feed quality.

Smallholder households tend not to be financially dependent on their pig production, because they keep pigs as a secondary business (Njombe \& Msanga 2009). This results in massive fluidity in people moving in and out of pig farming (Wabacha et al 2004a). Farmers seemed reluctant to keep records describing their pig production, although a few did state that they kept some form of records. Therefore, most of the answers given in the interview relied upon the farmers' recall, although validation by observation was used when possible.

\section{Animal welfare implications}

The welfare issues described here in the confinement system can all be easily avoided with extra attention and care for the animals, despite the limited resources available to the smallholder farmers. Simple improvements in smallholder pig management should be addressed in combination with any type of activity performed in smallholder pig production. However, research is needed to investigate the effect of improving pig management, and doing so only using local materials and the existing extension system, thereby making it sustainable.

Livestock keeping in Tanzania has focused, traditionally, on ruminants and pig-keeping has only recently become popular, reflected by the fact that pig numbers have increased exponentially in recent decades (FAOSTAT 2014). Most, if not all, of the welfare issues can be ascribed to a lack of knowledge and tradition about how this species should be kept. Education of farmers and extension officers on proper management in terms of animal welfare should therefore solve the most basic problems. Legislation covering welfare aspects is present in The Animal Welfare Act No 19 (2008), but the legislation is not enforced nor publicly available, and might therefore be better presented in a simple manner, which could be made available to the public and implementable in rural areas by smallholder farmers. The local extension officers could facilitate this implementation of the legislation but, since famers are unable to pay, large monetary fines should be discarded in the effort to implement the legislation. Instead, advocating for better growth and health in the herd, hence a larger profit, would be a better way forward.

\section{Acknowledgements}

The study was conducted under the SLIPP-project (Securing rural livelihoods through improved smallholder pig production in Mozambique and Tanzania) funded by the Danish International Development Agency (Danida), file no 09-007LIFE. Special thanks to Mr Simon Rwegayura for invaluable assistances both practical and logistical during the field work, and to Dr Eliakunda Kimbi for advice throughout. All farmers are acknowledged for their time and willingness to participate in the study.

\section{References}

BPEX 2009 Pigs Action for Productivity. http://www.bpex.org.uk/ Braae UC, Magnussen P, Lekule F, Harrison W and Johansen MV 2014 Temporal fluctuations in the sero-prevalence of Taenia solium cysticercosis in pigs in Mbeya Region, Tanzania. Parasites \& Vectors 7: 574. http://dx.doi.org /I0.1 I86/s|307|-0|4-0574-7

Braae UC, Ngowi HA and Johansen MV 2013 Smallholder pig production: Prevalence and risk factors of ectoparasites. Veterinary Parasitology 196: 24I-244. http://dx.doi.org/I0.10 I 6/j.vetpar.2012.12.058

FAOSTAT 2014 FAO (Food and Agriculture Organization of the United Nations) statistical databases. http://www.fao.org /statistics/en/

FAWC (Farm Animal Welfare Council) 2009 Farm Animal Welfare in Great Britain: Past, Present and Future. http://www.fawc.org.uk/reports.htm

Fraser D, Patience JF, Phillips PA, McLeese JM, Haresign W and Cole D 1990 Water for piglets and lactating sows: quantity, quality and quandaries. In: Haresign W and Cole DJA (eds) Recent Advances in Animal Nutrition PP 137-160. Butterworths: London, UK. http://dx.doi.org/10.1016/b978-0-408-04/508.500I4-I

Hemsworth P, Findlay J and Beilharz R 1978 The importance of physical contact with other pigs during rearing on the sexual behaviour of the male domestic pig. Animal Production 27: 20I-207. http://dx.doi.org/I0.10I7/S0003356100036035

Kabululu ML, Ngowi HA, Kimera SI, Lekule FP, Kimbi EC and Johansen MV 2015 Risk factors for prevalence of pig parasitoses in Mbeya Region, Tanzania. Veterinary Parasitology 2 I 2: 460 464. http://dx.doi.org//0.1016/j.vetpar.2015.08.006 
Kagira JM, Kanyari PWN, Maingi N, Githigia SM, Ng'ang'a JC and Karuga JW 2010 Characteristics of the smallholder free-range pig production system in western Kenya. Tropical Animal Health and Production 42: 865-873. http:// dx.doi.org/ | 0.1007/s I | 250-009-9500-y

Karimuribo E, Chenyambuga S, Makene V and Mathias S 20II Characteristics and production constraints of rural-based small-scale pig farming in Iringa region, Tanzania. Livestock Research for Rural Development 23: Article \#172

Knoesen J, Aucock H and Gardner M 1993 Housing Guidelines. In: Kemm (ed) Pig Production in South Africa. Bulletin No 427 pp II9128. Agricultural Research Council: Pretoria, South Africa

Komba EV, Kimbi EC, Ngowi HA, Kimera SI, Mlangwa JE, Lekule FP, Sikasunge CS, Willingham III AL, Johansen MV and Thamsborg SM 2013 Prevalence of porcine cysticercosis and associated risk factors in smallholder pig production systems in Mbeya region, southern highlands of Tanzania. Veterinary Parasitology 198: 284-29I. http://dx.doi.org/10.1016/j.vetpar.2013.09.020

Lekule FP and Kyvsgaard NC 2003 Improving pig husbandry in tropical resource-poor communities and its potential to reduce risk of porcine cysticercosis. Acta Tropica 87: III-II7. http://dx.doi.org/10.1016/S0001-706X(03)00026-3

Lynch PB, Cahill A, Lawlor P, Boyle L, O'Doherty J and Le Dividich J 2006 Studies on growth rates in pigs and the effect of birth weight. Report RMIS No 5220, Teagasc, Agricultural Food Development Authority, Moorepark, Fermoy, Co Cork, Republic of Ireland

Muhanguzi D, Lutwama V and Mwiine FN 2012 Factors that influence pig production in Central Uganda-Case study of Nangabo Sub-County, Wakiso district. Veterinary World 5: 34635I. http://dx.doi.org/I0.5455/vetworld.20 I2.346-35 I

Mutua FK, Dewey C, Arimi S, Ogara W, Levy M and Schelling E 2012 A description of local pig feeding systems in village smallholder farms of Western Kenya. Tropical Animal Health and Production 44: II57-I|62. http://dx.doi.org/|0.1007/s II2500l I-0052-6

Nannoni E, Martelli G, Cecchini M, Vignola G, Giammarco M, Zaghini G and Sardi L 2013 Water requirements of liquid-fed heavy pigs: Effect of water restriction on growth traits, animal welfare and meat and ham quality. Livestock Science 15 I: 21-28. http://dx.doi.org//0.1016/j.livsci.20I2.10.005

Ngowi HA, Kassuku AA, Maeda GEM, Boa ME, Carabin H and Willingham AL 2004 Risk factors for the prevalence of porcine cysticercosis in Mbulu District, Tanzania. Veterinary Parasitology 120 : 275-283. http://dx.doi.org/10.1016/j.vetpar.2004.01.015
Njombe AP and Msanga YN 2009 Livestock and dairy industry development in Tanzania. Department of Livestock production and Marketing Infrastructure Development, Ministry of Livestock Development 17, Tanzania

Patience JF 2012 The importance of water in pork production. Animal Frontiers 2: 28-35. http://dx.doi.org//0.2527/af.20I2-0037

Phengsavanh P, Ogle B, Stur W, Frankow-Lindberg BE and Lindberg JE 2010 Feeding and performance of pigs in smallholder production systems in Northern Lao PDR. Tropical Animal Health and Production 42: 1627-1633. http://dx.doi.org / 0.1007/s | |250-010-96/2-4

Schlink AC, Nguyen ML and Viljoen GJ 2010 Water requirements for livestock production: a global perspective. Revue Scientifique et Technique-Office International Des Epizooties 29: $603-$ 619. http://dx.doi.org//0.20506/rst.29.3.1999

Sikasunge CS, Phiri IK, Phiri AM, Dorny P, Siziya S and Willingham AL III 2007 Risk factors associated with porcine cysticercosis in selected districts of Eastern and Southern provinces of Zambia. Veterinary Parasitology 143: 59-66. http://dx.doi.org// 0.1016/j.vetpar.2006.07.023

URT 2014 Budget Speech Presented to Parliament by Minister for Livestock Development and Fisheries. Ministry of Livestock Development and Fisheries: Tanzania

Vosloo WA and Casey NH 1993 Pig production systems. In: Maree $\mathrm{C}$ and Casey NH (eds) Livestock Production Systems: Principles and Practice. Agri-Development Foundation: Pretoria, South Africa

Wabacha JK, Maribei JM, Mulei CM, Kyule MN, Zessin KH and Oluoch-Kosura W 2004a Characterisation of smallholder pig production in Kikuyu Division, central Kenya. Preventive Veterinary Medicine 63: 183-195. http://dx.doi.org/10.1016/j.prevetmed.2004.02.007

Wabacha JK, Maribei JM, Mulei CM, Kyule MN, Zessin KH and Oluoch-Kosura W 2004b Health and production measures for smallholder pig production in Kikuyu Division, central Kenya. Preventive Veterinary Medicine 63: 197-210. http://dx.doi.org/ 10.1016/j.prevetmed.2004.02.006

Welfare Quality ${ }^{\circledR}$ Protocol 2009 Welfare Quality ${ }^{\circledR}$ Assessment Protocol for pig (sows and piglets, growing and finishing pigs). Welfare Quality ${ }^{\circledR}$ Consortium: Lelystad, The Netherlands

Wilson RT 2013 Which way farm animal welfare in Tanzania? World Agriculture 4: 29-35 